\title{
Discrimination-reversal skills in squirrel monkeys: The reversal index and the reversal-acquisition ratio compared
}

\author{
M. A. JEEVES and A. H. WINEFIELD, University of \\ Adelaide. South Australia 5001
}

$A$ direct comparison is made of the reversal index and the reversal-acquisition ratio with a group of squirrel monkeys. The results indicate further merits and limitations of each as measures of discrimination-reversal skills in primates.

Rumbaugh \& Jeeves (1966) compared and contrasted two independently conceived discrimination-reversal indices, the reversal index (RI) proposed by Rajalakshmi \& Jeeves (1965), and the reversal/acquisition ratio (R/A) conceived by Rumbaugh \& Pournelle (1966). One of the points they emphasized was that since the RI entails the calculation of a single ratio it is better suited to organisms low in the phylogenetic scale, to whom it may be impossible to administer a long series of problems during their life span. The $R / A$ requires that a series of problems be administered so that an R/A function can be plotted, that is the R/A ratios against the $\mathbf{A} \%$ correct values. The data plotted by Rumbaugh and Pournelle were based on animals with a minimum of 1,800 trials of DR training and, in most cases, with previous experience in learning-set studies, "which entailed approximately 2,000 to 3,000 trials of either six-trial and/or criterional object-quality discrimination problems."

The advocates of R/A suggest that in the case of organisms high in the phylogenetic scale, and particularly primates, the calculation of many ratios entailed by the use of $R / A$ increases the intrinsic reliability of this index. This latter feature of R/A was believed to favor its use with primates over that of RI (Rumbaugh \& Jeeves, 1966). On the other hand, if it were found that assessments based on RI correlated highly in primates with those based on R/A then considerations of economy of time and effort would favor the use of the RI even with primates. The experiment reported below was therefore designed to study the relation of RI and R/A for a small group of primates (Saimiri Sciureus).

The argument is that if one assumes that $R / A$ is a valid indicator of learning ability in primates, then a high correlation between the rank ordering of a group of animals based on R/A with that based on RI would suggest (1) that the RI is a better indicator of learning ability for primates than had previously been thought, and (2) where considerations of economy of time and effort are important it could be used instead of $R / A$.

\section{METHOD \\ Phase 1}

A group of five adult squirrel monkeys (Saimiri Sciureus) learned to discriminate between patterns of horizontal vs vertical black and white stripes. Immediately on reaching a criterion of $18 / 20$ correct responses in two consecutive sets of 10 trials the signs of stimuli were reversed until the same criterion was again achieved. In this phase and in Phase 2, stimuli were presented according to the Gellerman series and a noncorrection training procedure was used. From these data the RIs for each animal were computed (Table 1).

Phase 2

The same group of Ss was presented with 100 different pairs of objects to discriminate. Eleven acquisition and eight reversal trials were given with each pair of objects. Thus all animals had a total of $1,900 \mathrm{DR}$ trials. At the end of this time they were performing consistently though only marginally above chance level on the acquisition trials. To increase the reliability of the R/A measure used it was decided to base it upon the data for all 100 pairs of objects. This seemed necessary since it is well known that where monkeys are performing only a little above chance level it is possible for marked object preferences to seriously distort the results if only a few pairs of objects are used, which by chance, happen to elicit strong approach or avoidance tendencies. The $\mathrm{R} / \mathrm{As}$ based on all 100 stimulus pairs for each animal were computed and are presented in Table 2.

In Phases 1 and 2 the $S$ s were $23 \mathrm{~h}$ food-deprived, were tested in a WGTA, and were rewarded with meal worms when they uncovered the food well by pushing the stimulus object aside.

\section{RESULTS AND DISCUSSION}

The animals were ranked according to performance based on the RI and $R / A$, respectively, and, as Tables 1 and 2 indicate, the rankings were identical.

This result is significant at better than the $1 \%$ level. The proponents of the $\mathrm{R} / \mathrm{A}$ have suggested that the $\mathrm{A} \%$ should be approximately the same for animals for whom the $R / A$ is to be used for comparative purposes. In their paper the $A \%$ range is from 81.70 to $88.75 \%$. Since in the present experiment the A\% correct covered a smaller range of from 52.36 to $57.27 \%$, it was felt legitimate to use the $\mathrm{R} / \mathrm{A}$ to compare the five animals.

It might be questioned whether it is desirable to base any sort of DR ratio on data which indicates that the animals were performing only slightly above chance level on the grounds that there is only weak evidence that learning has taken place, but if no learning had taken place then one would expect the percentage of correct responses to be the same on acquisition as on reversal. Any chance effects due to object preference would presumably be cancelled out over 100 object pairs. However, if the animals are learning during the acqusition phase then one would expect negative transfer in the reversal phase and consequently an R/A ratio of less than unity. A

Table 1

Number of Trials Required to Learn Discrimination and Reversal and the RIs Based on these Data

\begin{tabular}{lcccc}
\hline Animal & Trials to Discrimination & Trials to Reverse & RI & Rank on RI \\
\hline Magoo & 360 & 190 & 0.528 & 1 \\
Morgan & 280 & 310 & 1.107 & 2 \\
Brutus & 360 & 410 & 1.139 & 3 \\
Cecil & 370 & 480 & 1.297 & 4 \\
Socrates & 170 & 430 & 2.529 & 5 \\
\hline
\end{tabular}

Table 2

A\%, R\%, and R/A Ratios for Each Animal Based on 100 object Discrimination Pairs

Animal Performance on 100 Object Discriminations Rank on R/A A\% $\quad$ R\% $\quad$ R/A

\begin{tabular}{lllll}
\hline Magoo & $53.45 \%$ & $50.50 \%$ & .945 & 1 \\
Morgan & $52.36 \%$ & $48.63 \%$ & .929 & 2 \\
Brutus & $53.64 \%$ & $49.63 \%$ & .925 & 3 \\
Cecil & $57.27 \%$ & $49.00 \%$ & .856 & 4 \\
Socrates $54.82 \%$ & $46.13 \%$ & .842 & 5
\end{tabular}


Table 1

Mean and Range of Total Errors Across 20 Spatial Problems

\begin{tabular}{llll}
\hline & Capuchin & Squirrel & Owl \\
\hline Mean & 54.2 & 208.2 & 170.0 \\
Range & $30-75$ & $150-310$ & $120-235$ \\
\hline
\end{tabular}

both measures. As Figs. 1 and 2 suggest, the Capuchins were appreciably superior to the Squirrel and Owl monkeys in reducing errors across the 20 problems. However, there was considerable overlap by $\mathrm{OWl}$ and Squirrel scores on both measures. Only on the second and third problems, which typically generate the greatest amount of negative transfer with most other vertebrates, was there a prominant difference between performances of Owls and Squirrels. Both groups appeared to be approaching asymptotic performance equal to that of the Capuchin, e.g., one error per problem.

The similarity of Owl and Squirrel SDR performances are of considerable interest in view of their traditionally assigned taxonomic status. Squirrel monkeys (Samiri) are usually grouped with the Capuchins in the subfamily Cebinae, while the Owls are assigned to a presumably phyletically inferior subfamily Aotinae (Simpson, 1962). However, there has been considerable controversy concerning the placement of the Squirrel in Cebinae. Some authors (Hill, 1960) have argued that Samiri are more closely related to Owl monkeys (Aotoes) than to the Capuchin (Cebus) on both morphological and behavioral grounds. To the extent that similarity of patterns of such performances as that measured by SDR are diagnostic of interspecies taxonomic distances 2 the data reported above would provide additional support for this argument.

\section{REFERENCES}

BITTERMAN, M. E. The evolution of intelligence. Scientific American, 1965, 212,92-100.

GOSSETTE, R. L. Comparisons of successive discrimination reversal (SDR) performances across fourteen different avian and mammalian species. American Zoologist, 1966, 6. (Abstract)

GOSSETTE, R. L., GOSSETTE, M., \& RIDDELL, W. Comparisons of successive discrimination reversal performances among closely and remotely related avian species. Animal Behavior, 1966, 14, 560-564.

GOSSETTE, R. L., \& INMAN, N. Comparison of spatial successive discrimination reversal performances of two groups of New World monkeys. Perceptual \& Motor Skills, 1966, 23, 169-170.

HILL, W. C. O. Primates. Vol. IV. Cebidae. Edinburgh: Edinburgh University Press, 1960.

SIMPSON, G. G. Primate taxonomy and recent studies of nonhuman primates. Annals of the New York Academy of Sciences, 1962, 102, 497-514.

\section{NOTES}

1. Supported in part by NIMH Grant No. 14079-01 awarded to first author.

2. Gossette, R. L. Successive discrimination reversal measures and interspecies taxonomic distance. Unpublished manuscript.
Table 3

R/A Comparison with Results of Rumbaugh \& Pournelle (1966)

\begin{tabular}{lcc}
\hline & Rumbaugh \& Pournelle $(\mathrm{N}=7)$ & Present Study $(\mathrm{N}=5)$ \\
\hline Mean & .899 & .894 \\
Standard deviation & .044 & .049 \\
Range & .110 & .131 \\
\hline
\end{tabular}

comparison of the $\mathrm{R} / \mathrm{A}$ ratios for the five animals based on all 100 object pairs shows that the mean value departs significantly from $1.00(t=4.42, \mathrm{df}=4, \mathrm{p}<.01$, on a one-tailed test). In other words there is clear evidence that learning was occurring.

The remarkable similarity between our $R / A$ ratios and those based on Rumbaugh \& Pournelle's (1966) data requires comment. Table 3 compares the mean R/A values for this study and the Rumbaugh and Pournelle study and indicates that the mean, the standard deviation, and the range were very close indeed. On the one hand, this similarity could be interpreted as evidence in favor of the robustness of the R/A ratio and its relative independence of previous learning and any slight differences in procedure. On the other hand, it could be interpreted as evidence that the $R / A$ ratio is somewhat insensitive to genuine differences in learning ability. Since Rumbaugh and Pournelle state that "these particular squirrel monkeys were superior in their DR skills, for they had been selected for use as Ss in the Rumbaugh and Ensminger study by reason of their relatively high-order learning-set performance in earlier experiments," one might have hoped that the R/A ratio for their animals would have differentiated them from the randomly-selected animals used in this study. In this respect there seems to be something to be said in favor from page 221)

of the RI when making comparisons between animals of the same species. The spread of values for RI for the five animals in this study is from 0.528 to 2.529 . By comparison, the R/A values are very closely clustered together-from .814 to .945 in the present study, and from .866 to .976 in the Rumbaugh and Pournelle study. In fact, four values out of the seven are almost the same, i.e., $.866, .866, .867$, and 868 .

The $100 \%$ correspondence between the RI and R/A ranking increases our confidence in the suitability of the RI for use with primates as well as subprimates. It is worth noting that whereas the time taken to gather the data for RI calculations ranged from 8 days to 34 days, it took from 33 days to 57 days to collect the data to compute the $R / A$. A further limitation of R/A is the stipulation that it should only be used when the $A \%$ s are approximately equal; with subprimates this is highly unlikely, although the present experiment shows that with primates of the same species, the chances are better. This requirement of equivalent $\mathrm{A} \% \mathrm{~s}$ would, however, make it difficult to use the R/A for making ontogenetic comparisons with primates within the same species. By comparison the RI has been shown to reflect ontogenetic differences (Jeeves, 1967).

JEEVES, M. A. The reversal index and ageing. Psychonomic Science, 1967, 9, 371-372.

RAJALAKSHMI, R., \& JEEVES, M. A. The relative difficulty of reversal learning (reversal index) as a basis of behavioural comparisons. Animal Behaviour, 1965, 13, 203-211.

RUMBAUGH, D. M., \& JEEVES, M. A. A comparison of two discrimination-reversal indices intended for use with diverse groups of organisms. Psy chonomic Science, 1966, 6, 1-2.

RUMBAUGH, D. M., \& POURNELLE, M. B. Discrimination-reversal skills of primates: The reversal/acquisition ratio as a function of phyletic standing. Psy chonomic Science, 1966, 4, 45-46. 